\title{
Tobacco use and the United States military: a longstanding problem
}

Ties between the United States military and the tobacco industry trace back to the early parts of the 20th century. During the second world war, for example, cigarette advertisements praising service members were widespread on popular radio programmes and in periodicals. ${ }^{1}$ Some ads even featured cigarette-using doctors vouching for the great taste and mildness of particular brands. Cigarettes were also included as part of the K-rations and C-rations provided to soldiers and sailors during the second world war, and these cigarettes frequently became more valuable for trading or selling than the food items in the rations.

During times of war and peace, many young people (predominantly men, as they have traditionally comprised the bulk of military personnel) started smoking after they joined the military. In fact, it has been widely acknowledged in military circles that many young soldiers and sailors first started smoking during their initial military "boot camp" training. Before 1987, when tobacco use was banned at most training commands across the military services, giving or denying "smoke breaks" was a common form of reward and punishment used by drill instructors and company commanders training new soldiers or sailors. ${ }^{2}$ If recruits did not already smoke when they entered the military, in boot camp they quickly learned that smoking to get a work break was a desirable thing to do. Even beyond recruit training, the military culture-at least until relatively recently - has traditionally fostered the stereotype of heavy-smoking, hard-drinking, and adventuresome service members.

This image has had empirical support from several studies indicating that military rates of tobacco and alcohol use have been higher than those found in comparable civilian sectors..$^{3-7}$ As of 1995, however, the military/civilian differences in tobacco use have narrowed. ${ }^{8}$ Considering all the services combined, the differences between the military and standardised civilian samples reach statistical significance only among young 18-25 year old men. However, differences exist across the different branches of the service. For example, male marines and navy men overall have significantly higher smoking rates than civilian men; younger army men under 26 years of age have statistically higher rates of smoking than civilian men. Air force men, in contrast to the other services, have lower smoking rates overall than civilian men. These trends are similar for women military personnel, although the differences between military and civilian women are much smaller and typically are not statistically significant. ${ }^{8}$

Parallelling civilian-sector efforts during the 1980s, the Department of Defense (DoD) increased health promotion efforts aimed at improving health and physical readiness. $^{910}$ Among these were programmes to curb tobacco use among military personnel. And, in fact, smoking in the military has decreased dramatically since $1980,{ }^{11}$ parallelling trends observed in the civilian sector. However, the prevalence of tobacco use currently is still well above the Healthy people 2000 goal of no more than $20 \%$ smokers in the military. ${ }^{12}$ Furthermore, the high rates of smoking among military personnel persist after discharge from military service. Compared with non-veterans, veterans are more likely to be current smokers. ${ }^{13} 14$

Smoking among American service members is an important factor that can influence military readiness. Several studies have reported data indicating that there are negative relationships between smoking and various measures of "performance readiness". Smokers exercise less and perform more poorly on physical fitness tests, ${ }^{15-17}$ and they are less successful in combat training. ${ }^{18}{ }^{19}$ Smokers also have higher rates of various types of illnesses and absenteeism from the job. ${ }^{21}$ The effects of regular tobacco use clearly are incompatible with maintaining the physical abilities necessary to perform at peak levels in the very physically demanding jobs that are commonplace in the military.

Data presented by Haddock et $a l^{22}$ in this issue of Tobacco Control provide further evidence that smoking is still a matter for concern even among air force personnel, who have lower smoking rates than all of the other services. Not only is regular smoking quite prevalent among entering air force recruits (32\% during 1995-1996), but Haddock and colleagues also found that regular smoking before entering training was associated with other risk factors believed to lower military readiness. Compared with air force recruits who had not smoked regularly before entering training, those who were smokers were more likely to report higher alcohol use, more frequent binge drinking, more smokeless tobacco use, and less physical activity. As Haddock et al point out, their data add to the growing body of literature indicating that smokers tend to engage in clusters of unhealthy behaviours.

Given that the rates of cigarette smoking among United States military personnel tend to be higher than smoking rates in the civilian sector, a logical question to ask is whether the military "attracts" or "creates" smokers. That is, are the higher rates of smoking in the military a result of self-selection of smokers joining the services, or are there aspects of the military environment and institutional norms that promote smoking among its members? One of the earliest studies to address this question was a cross-sectional comparison of United States Navy male shipboard personnel with incoming recruits conducted in the mid-1980s before the smoking ban in recruit training. ${ }^{23}$ Although design limitations necessarily temper inferences that can be drawn from this study, findings did suggest that the military experience fostered cigarette use. Similarly, a longitudinal examination of the patterns of smoking initiation among male recruits during their first year in the navy (conducted during 1986, before the recruit training smoking ban) showed an increase in their smoking rate by 12 percentage points $(28 \%$ to $40 \%){ }^{24}$

The study by Chisick, Poindexter, and York ${ }^{25}$ in this issue of Tobacco Control addresses the issue of whether the military environment somehow encourages service members to initiate tobacco use on a much larger scale than did these earlier small studies on navy personnel. Using a cross-sectional survey design, data on tobacco use that were collected during 1994 in conjunction with dental examinations compared random samples of new recruits and active duty personnel from all four branches of the military. Chisick and colleagues' data indicate that tobacco use rates were significantly higher among active duty men than among incoming male recruits. Although the data are cross-sectional, their findings suggest that exposure to the military environment might lead to increases in tobacco use by young enlisted men; however, the data for women did not show a similar pattern. 
One caveat regarding the findings presented by Chisick et $a l^{25}$ is that it is likely the methods used to estimate smoking rates produced some bias toward underrepresenting tobacco use among new military recruits. A smoker, for example, was defined as someone who answered "yes" to the question: "Do you smoke cigarettes now?" As recruits were asked this question during in-processing, which occurs during the first three days following arrival at a basic training centre, they were already in an environment that prohibited any form of tobacco use at any time (a total ban from the moment they arrived at the training centre). It is likely, therefore, that some recruits who would have been defined as smokers using other usual criteria - for example, smoked a cigarette during the past 30 days - were instead defined as non-smokers because they responded literally and said "no" to the question about whether they smoked "now"-which was prohibited under the training centre's tobacco ban.

Nonetheless, Chisick and colleagues make the important point that the challenge to military policy makers is to find ways to curb the initiation of tobacco use that may occur as a result of exposure to the military environment. ${ }^{25}$ This challenge is enhanced by findings indicating that there are substantial differences in tobacco use rates by branch of service, gender, and race. These differences suggest that multiple strategies for various subgroups may be warranted both for preventing initiation among new service personnel who do not smoke when they enter the military, as well as for cessation efforts to help those who already use tobacco to quit.

For some time now, military policy makers have had a keen interest in reducing the high rates of smoking among its personnel because of the known negative health and readiness effects. In addition to the negative associations between smoking and physical readiness, smoking-related healthcare costs in the DoD are estimated at about $\$ 530$ million a year and associated lost productivity costs are at about $\$ 345$ million. ${ }^{26}$ Developing cost-effective strategies to prevent initiation of smoking and to help smokers quit is, therefore, a priority from a military healthcare planning perspective. $^{27}$

Banning tobacco use entirely during recruit training, which was done at most training centres about 1987, was an important step in starting to modify aspects of the military environment to reduce tobacco use among service members. Non-smokers coming into the military now at least do not start smoking during boot camp training, as certainly was the case before the ban. ${ }^{24}$ Furthermore, the tobacco use ban during recruit training probably helps a higher percentage of smokers quit and to stay quit at a rate higher than would be expected without the ban. ${ }^{28}{ }^{29}$ It is also impressive that the Department of Defense now has the distinction of being the largest employer in the United States with a worksite ban on tobacco use that prohibits smoking within all its buildings. This too is an important step, as restrictive smoking regulations seem to have a significant effect on cigarette consumption. ${ }^{30-32}$

In addition to these regulations, further reductions in military tobacco use rates are likely to require stepped-up efforts involving educational, motivational, and social/ environmental changes. Stronger educational messages, including ones orientated toward changing social norms regarding smoking in the military, could be initiated in recruit training. Further support for continued non-smoking after leaving the 24-hour-per-day tobacco use ban imposed during recruit training could also be very useful for new graduates of recruit training. Unfortunately, the first thing many recruits want to do immediately after leaving the restrictive environment of recruit training is to exercise the "personal freedom" to smoke as soon as they are able. In addition, many work settings to which recruit training graduates are first assigned involve a lot of "hurry up and wait" time, where individuals fluctuate between being stressed and bored. In fact, some of the most common reasons new military members give for smoking after leaving recruit training are to deal with stress, boredom, or just to be sociable in a new job setting. As Haddock and colleagues found in their data ${ }^{22}$ the strongest predictors of smoking among air force recruits were social, such as having more friends who smoke and viewing smoking as more "socially attractive". Thus, a promising approach to reducing military tobacco use might focus on changing social norms regarding the attractiveness of smoking and encouraging groups of friends to support each other's attempts to become or remain smoke-free.

Also, as pointed out by Chisick and colleagues, ${ }^{25}$ some of the military's own contradictory co-existing policies on tobacco might be contributing to its tobacco use problem. For example, despite the total tobacco use ban during recruit training, worksite bans on smoking in DoD buildings, and a wide variety of smoking cessation programmes, discounted cigarettes are still readily available in commissaries and exchanges at prices substantially lower than in the surrounding civilian community. It is estimated that commissaries total about $\$ 458$ million in tobacco sales per year. ${ }^{26}$ Part of the profits from these tobacco sales go to military Morale, Welfare, and Recreation (MWR), which provides many positive "health and welfare services" for the troops. Thus, there are clearly contradictory forces working when it comes to reducing cigarette sales at the cost of monetary profits that go to help military personnel through this channel.

There are many inherent difficulties in trying to eliminate a behaviour - tobacco use - that many individuals in the military firmly believe is a right and personal freedom that they should not be forced to give up. Yet, it is equally clear that tobacco use is incompatible with the requirements for optimal health and physical readiness that are essential for military forces to perform at peak levels. Military policy makers should be commended, especially given the historical traditions involving tobacco use, for making many quite aggressive changes since the early 1980s aimed at reducing rates of tobacco use among American service members. Strong additional efforts, however, are necessary to reach the Healthy people 2000 goal of no more than $20 \%$ military smokers, ${ }^{12}$ and for the military to reach its own goal of becoming smoke-free. Key to reaching these goals is strong leadership from top levels down, with the most senior leaders down to the most junior leaders setting examples and standards for good health and fitness. Strong leadership can change military social norms in the direction of unacceptability of tobacco use, which would have a significant impact on tobacco use among service members - and this is a reachable goal, as the United States military knows a lot about leadership.

San Diego State University,

TERRY L CONWAY

9245 Sky Park Court, Suite 120,

San Diego, California 92123-4311, USA.

tconway@mail.sdsu.edu

1 Blake GH. Smoking and the military. NY State f Med 1985;85:354-6.

2 Cronan TA, Conway TL. Evaluation of smoking interventions in recruit training. Mil Med 1989;154:371-5.

3 US Department of Health and Human Services. Reducing the health consequences of smoking: 25 years of progress. A report of the Surgeon General, 1989. Rockville, Maryland: Public Health Service, Centers for Disease Control, Office on Smoking and Health, 1989. (DHHS Publication No (CDC) 89-8411.)

4 Bray RM, Marsden ME, Peterson MR. Standardized comparisons of the use of alcohol, drugs, and cigarettes among military personnel and civilians. Am $\mathcal{F}$ Public Health 1991;81:865-9. 
5 Bray RM, Guess LL, Marsden ME, et al. Prevalence, trends, and correlates of alcohol use, nonmedical drug use, and tobacco use among US military

6 Conway TL, Trent LK, Conway SW. Physical readiness and lifestyle habits among US navy personnel during 1986, 1987, and 1988. Technical Report No 89-24. San Diego, California: Naval Health Research Center, 1989.

7 Ballweg JA, Bray RM. Smoking and tobacco use by US military personnel. Mil Med 1989;154:165-8.

8 Bray RM, Kroutil LA, Wheeless SC, et al. 1995 Department of Defense survey of health related behaviors among military personnel. Report No RT/6019/06FR. Research Triangle Park, North Carolina: Research Triangle Institute, 1995.

9 Department of Defense. DoD Directive 1010.10, Health promotion (NOTAL). Washington, DC: Department of Defense, 11 March 1986.

10 Secretary of the Navy. SECNAV INSTRUCTION 6100.5 Health Promotion Program. Washington, DC: Department of the Navy, 17 September 1986.

11 Kroutil LA, Bray RM, Marsden ME. Cigarette smoking in the US military: findings from the 1992 Worldwide Survey. Prev Med 1994;23:521-8.

12 US Department of Health and Human Services. Healthy people 2000: national health promotion and disease prevention objectives. Washington, DC: US Government Printing Office, 1991. (DHHS Publication No (PHS) 91-50212.)

13 Feigelman W. Cigarette smoking among former military service personnel: a neglected social issue. Prev Med 1994;23:235-41.

14 Klevens RM, Giovino GA, Peddicord JP, et al. The association between veteran status and cigarette-smoking behaviors. Am f Prev Med 1995;11:24550.

15 Conway TL, Cronan TA. Smoking and physical fitness among Navy shipboard personnel. Mil Med 1988;153:589-94

6 Conway TL, Cronan TA. Smoking, exercise, and physical fitness. Prev Med 1992;21:723-34

17 Bahrke MS, Baur TS, Poland DF, et al. Tobacco use and performance on the US Army physical fitness test. Mil Med 1988;153:229-35.

18 Zadoo V, Fengler S, Catterson M. The effects of alcohol and tobacco on troop readiness. Mil Med 1993;158:480-4.
19 Blake GH, Parker JA. Success in combat training: the role of cigarette smoking. F Occup Med 1991;33:688-90.

20 Kristen MM. How much can business expect to profit from smoking cessation? Prev Med 1983;12:358-81.

21 US Centers for Disease Control. Medical care expenditures attributable to cigarette smoking-US, 1993. MMWR 1993;43:469-72.

22 Haddock CK, Klesges RC, Talcott GW, et al. Smoking prevalence and risk factors for smoking in a population of United States Air Force basic trainees. Tobacco Control 1998;7:232-5.

23 Cronan TA, Conway TL. Is the Navy attracting or creating smokers? Mil Med 1988;153:175-78.

24 Cronan TA, Conway TL, Kaszas SL. Starting to smoke in the Navy: when, where, and why? Soc Sci Med 1991;33:1349-53.

25 Chisick MC, Poindexter FR, York AK. Comparing tobacco use among incoming recruits and military personnel on active duty in the United States. Tobacco Control 1998;7:236-40.

26 Military smoking report. US Med 1997 Feb:161.

27 Miller MJ, Ortmeier BG, Draugalis JR, et al. A retrospective analysis of the costs and consequences of a tobacco-cessation program for active duty service members. Mil Med 1996;161:420-4.

28 Hurtado SL, Conway TL. Changes in smoking prevalence following a strict no-smoking policy in US Navy recruit training. Mil Med 1996;161:571-6.

29 Woodruff SI. The epidemiology of smoking among US Navy women recruits: prevalence, correlates, and short-term effects of involuntary cessation. Doctoral dissertation, San Diego State University-University of California, San Diego Joint Doctoral Program in Epidemiology, 1998.

30 Rigotti NA, Pashos CL. No-smoking laws in the United States: an analysis of state and city actions to limit smoking in public places and workplaces. fAMA 1991;266:3162-7.

31 Simonich WL. Government antismoking policies. New York: Peter Lang, 1991.

32 Wasserman J, Manning WG, Newhouse JP, et al. The effects of excise taxes and regulations on cigarette smoking. f Health Econ 1991;10:43-64.

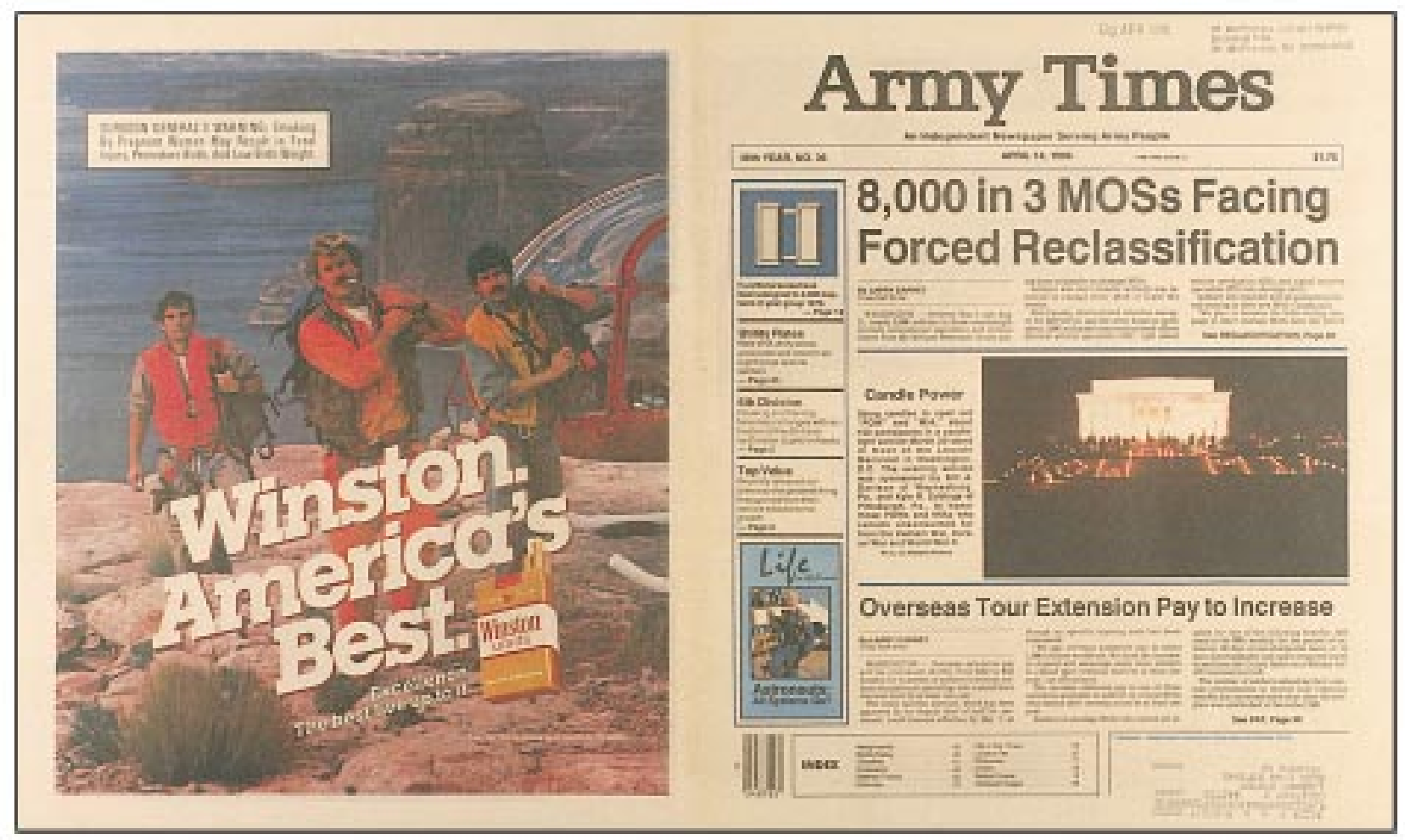

Cigarettes have been advertised prominently in "Army Times", "Navy Times", and "Air Force Times". 